\title{
Amelias 3, la vida en un asentamiento informal a través de la mirada de cuatro jefas de hogar ${ }^{1}$
}

\author{
Alejandro De Sárraga Montoya
}

Artículo

\begin{abstract}
Resumen
La vida en los asentamientos informales; conlleva una serie de factores que se diferencian de otras formas de convivencia. Algunos son físicos, como la autoconstrucción de vivienda y el uso ilegal de los servicios básicos, otros contienen un carácter social, como el manejo de los conflictos y los actos de solidaridad. Saber cómo es normalmente un día en un asentamiento informal permite comprender las prácticas que se desarrollan en este espacio, las dificultades que afrontan, cuáles son las motivaciones para establecerse en precarios ${ }^{2}$ y también cómo es su estructura organizacional. A través de la entrevista a cuatro jefas de hogar del asentamiento Amelias 3 , se abordarán estos temas.
\end{abstract}

Palabras clave: asentamiento informal; diario vivir; informalidad; jefas de hogar; relaciones vecinales.

Amelias 3, life in an informal settlement through the eyes of four home female householders

\begin{abstract}
:
Life in informal settlements entails a series of factors that differ from other forms of coexistence. Some are physical, such as the self-construction of housing or the irregular use of basic services, while others are rather social, like the handling of conflicts or the acts of solidarity. Knowing how is a normal day in an informal settlement allows us to understand the practices that take place in this space, the difficulties that residents face, the reasons why people settle in it and also known about the organizational structure. To try to answer some of these topics, I interviewed four housewives from Amelias 3 settlement.
\end{abstract}

Alejandro De Sárraga Montoya
Bachiller en Antropología y Licenciado en Antropología Social por la Universidad de Costa Rica.
Keywords: Informal settlement; daily life; informality; female heads of household; neighborhood relations.
1 El presente artículo se desprende de mi investigación de tesis, titulada: Cambio en las relaciones vecinales al efectuarse un traslado de un asentamiento informal a un condominio, en Los Cuadros de Purral, Goicochea, San José; para optar por el grado de Licenciatura en antropología social.

2 Denominación costarricense de los asentamientos informales. 


\section{Introducción}

I estudio de los asentamientos informales debe tomar en consideración el desarrollo de la vida en su interior, de esta forma se puede tener una mayor claridad de las dinámicas sociales que se producen, y a su vez propiciará una perspectiva interna de los diferentes temas adscritos a esta forma de vivir, como lo son: la informalidad y el diseño urbano.

Los asentamientos informales pueden ser vistos de la siguiente manera:

"áreas residenciales en las cuales 1) los habitantes no ostentan derecho de tenencia sobre las tierras o viviendas en las que habitan, bajo las modalidades que van desde la ocupación ilegal de una vivienda hasta el alquiler informal; 2) los barrios suelen carecer de servicios básicos e infraestructura urbana. $Y 3$ ) las viviendas podrían no cumplir con las regulaciones edilicias y de planificación y suelen estar ubicadas geográfica y ambientalmente en áreas peligrosas." (ONU Hábitat, 2015, p. 1)

Nacen "producto de las llamadas "tomas de tierra", organizadas o no, los cuales, unos más que otros, con el tiempo, ven mejoradas ciertas condiciones, como la infraestructura de las viviendas y el acceso a servicios" (Instituto de Estadística y Censo, 2011, p. 8). Se añade que son el fruto de la necesidad de vivienda, ya que, en la mayoría de los casos sus residentes no cuentan con los medios económicos para comprar o alquilar una casa dentro del sistema inmobiliario regulado (muchas de las familias se encuentran en condición de pobreza y hasta pobreza extrema).

A partir de los motivos y las acciones que dan nacimiento y desarrollo a los asentamientos informales surge la siguiente pregunta, ¿qué características físicas y sociales tiene este espacio? Con la intención de encontrar la respuesta, se entrevistó a cuatro jefas de hogar': Rosa, Luz, Margarita y Consuelo, que residieron en el asentamiento informal Amelias 3 (ubicado en Los Cuadros, del distrito Purral del cantón Goicoechea, de Costa Rica) por más de 10 años y hasta el $2016^{4}$.

El presente artículo se divide en cinco partes. La primera indica el enfoque teórico, y la técnica metodológica. Se continúa con la mención de las políticas de vivienda de Costa Rica y con una leve descripción de la situación actual de los asentamientos informales. Seguidamente, se hace una contextualización histórica, económica y habitacional de Los Cuadros ${ }^{5}$. Posteriormente, se detallan las características físicas y sociales de Amelias 3. Se cierra el artículo con la puntualización de las conclusiones.

Se debe recalcar que la investigación se enmarca dentro de los estudios urbanos, más específicamente bajo el enfoque de las formas de vida y vivienda en la informalidad. Tema que ha sido tratado en América Latina desde hace más de cuatro décadas por los siguientes autores Abramo (2011), Bäbr, Jürgen, y Borsdorf (2005), Centro Cooperativo Sueco (2003), Harvey (1977), Morales (1984) y Rapaport (1988).

\section{Etnografía, Epistemología del Sujeto Conocido y metodología}

$3 \quad$ El nombre de las participantes ha sido reemplazado por un seudónimo. Para el caso de doña Margarita no se cuenta con citas verbales, por solicitud expresa de ella.

\section{$4 \quad$ Las entrevistas fueron realizadas en} 2016 y 2018. En las nuevas residencias de las jefas de hogar, que se localizan en un condominio de interés social a 300 metros del asentamiento. En total se realizaron 10 entrevistas.

$5 \quad$ Lo anterior, bajo la justificación de que es un lugar de gran influencia en el desenvolvimiento del asentamiento.
En busca de contar con una teoría investigativa que permita desarrollar un trabajo cercano y humano con las colaboradoras, se optó por emplear la Etnografía. Esta hace referencia a "la descripción de lo que una gente hace desde la perspectiva de la misma gente (...) le interesa tanto las prácticas (lo que la gente hace) como los significados que estas prácticas adquieren para quienes las realizan» (Restrepo 2018, p. 25). Además, tiene como estrategia de investigación, buscar: "una comprensión densa y contextual de un escenario concreto, desde el cual se pueden establecer conexiones y conceptualizaciones con otras realidades" (p. 25).

Para complementar la etnografía, se añade la Epistemología del Sujeto Conocido (ESC), el cual es trabajado por Irene Vasilachis e indica que el investigador debe ver al otro como igual en su condición humana. Esta perspectiva entiende que las personas son fuente de conocimiento válido y no emisores a los cuales se debe interpretar, reconociéndolos como sujetos y no como objetos. En este contexto, el proceso de conocimiento es tratado como "una construcción cooperativa en la que sujetos esencialmente iguales realizan aportes diferentes" (Vasilachis, 2013, p. 30). 
La escogencia de la etnografía y la ESC como herramientas teóricas se basa en el hecho de que permiten ver las representaciones, sentires y visiones de doña Rosa, Consuelo, Luz y Margarita, bajo una condición humana integral y no como simples fuentes de información. Esto permite que los temas de investigación surjan a partir de las jefas de hogar y no de determinaciones preestablecidas, además les da un rol activo en la creación de conocimiento.

Sumado a lo anterior, los ejes conceptuales del artículo son las relaciones vecinales y la identidad comunitaria. La primera se entiende como "actividades llevadas a cabo por vecinos en cuanto vecinos como a las relaciones que estas actividades engendran entre ellos" (Keller, 1979, p. 36), es decir, son las actividades que se dan entre vecinos los cuales se encuentran mediados por una serie de expectativas que el individuo tiene con respecto a cómo debe actuar y comportarse un vecino. La identidad comunitaria por su parte hace referencia a "las interacciones sociales que tienen un grupo de individuos (que comparten un lazo) en un lugar específico y por el cual llegan a sentir una identificación y filiación" (De Sárraga, 2020, p. 35). Bajo los ejes conceptuales, el estudio de la vida en Amelias 3 se da a través del marco con que las entrevistadas veían el comportamiento de sus vecinos (ya sea positivo o negativo). Asimismo, permite analizar el grado de identificación que tienen con respecto al lugar.

El contacto con las colaboradoras se da gracias a la ayuda de la Fundación Promotora de la Vivienda (FUPROVI). La Fundación me presenta a la señora Rosa, quien en su momento era la administradora del condominio La Esperanza (lugar donde realicé mi trabajo de campo). Ella a su vez me presentó al resto de las entrevistadas.

Para dar respuesta a la pregunta de investigación y trabajar de manera acorde a la etnografía y la ESC, se decidió emplear la entrevista cualitativa, esta busca "obtener datos preguntando a los sujetos, pero con el objetivo característico de la investigación cualitativa de conocer la individualidad de la persona entrevistada y ver el mundo con sus ojos" (Corbetta, 2007, p. 344). La técnica se efectuó bajo el formato de entrevista semi-estructurada ${ }^{6}$. En otras palabras, se contaba con una batería de preguntas (nacimiento del asentamiento, relación vecinal entre otros) que servía como guía de los temas a tratar, pero que no fijaban las conversaciones a la contestación de las mismas. Más bien facilitaba que las colaboradoras pudieran expresarse con total libertad sobre sus vidas en Amelias 3 y las características físicas y sociales de su hogar y entorno. También se tomaron fotografías.

\section{Política Nacional de vivienda y situación actual de los asentamientos informales}

La política nacional de vivienda comienza en el año 1904 con la Ley de Chinchorros, pero es a partir de la década de 1940 que el Estado consolida la creación de leyes e instituciones enfocadas a atender el tema en cuestión, la figura 1 presenta una línea temporal de las leyes e instituciones creadas hasta la fecha.

Figura 1. Instituciones y leyes de vivienda creadas en Costa Rica.

Fuente: Elaboración propia.

$6 \quad$ Las transcripciones se exponen con las palabras exactas de las colaboradoras. Las entrevistadas realizadas se dieron entre el 2016 y el 2018, en las fechas donde tuvieran tiempo para recibirme.

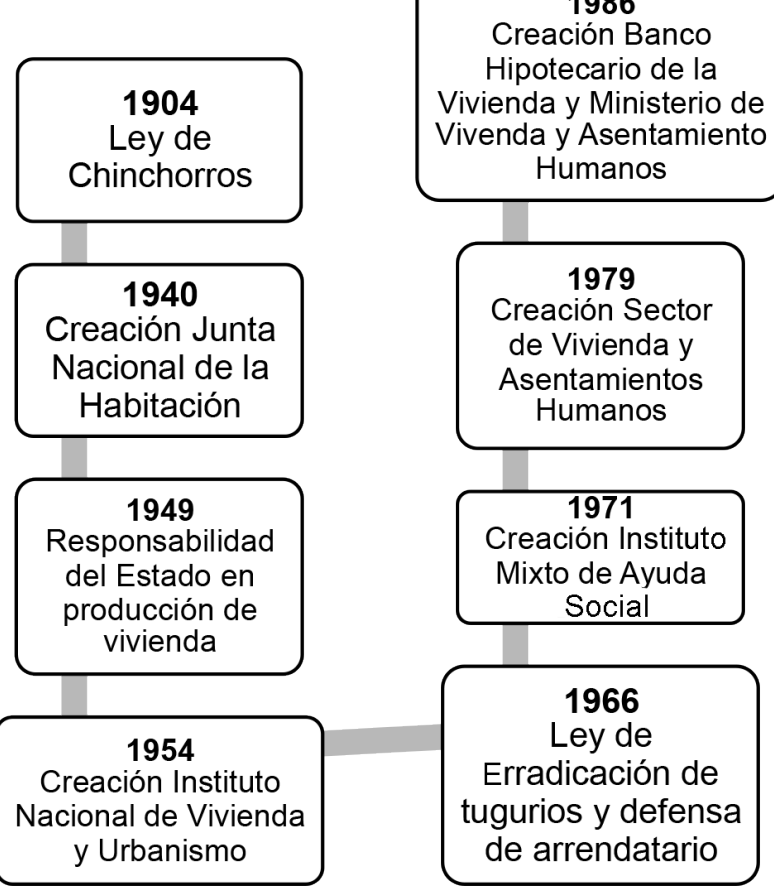


Se destaca la creación del Banco Hipotecario de la Vivienda debido a que, dentro de la ley № 7052 que lo creó, se incluyó el nacimiento del Fondo de Subsidios de la Vivienda (conocido popularmente como bono de vivienda). El bono está bajo la administración del banco y su función es "pagar una parte del costo de una solución de vivienda (...) lograr que las familias de escasos recursos tengan la posibilidad de adquirir vivienda en el mercado" (Morgan, s.f., p. 8). Esto ayuda, por ejemplo, a que personas que residen en asentamientos informales puedan pasar a contar con un título de propiedad y una vivienda propia.

Uno de los propósitos por los cuales nacieron estas leyes e instituciones fueron para tratar el tema de los asentamientos informales, ya sea en procura de erradicarlos o de transformarlos en barrios y viviendas formales. Pero existe un problema al momento de tratar este tema y es que "puede decirse que el país no cuenta con una información certera y actualizada sobre la cantidad de población en general y de familias u hogares en asentamientos informales y su situación particular" (Fundación Promotora de la Vivienda, 2018, p. 45). Esta situación afecta el impacto de los planes y estrategias diseñadas para atender los asentamientos informales y a sus residentes.

Con respecto a cuáles son las raíces que generan la existencia de los asentamientos, FUPROVI indica: "Mientras no se controlen o superen las causas estructurales como la pobreza, la desigualdad social y los problemas de acceso al suelo, el problema de los asentamientos informales seguirá presente" (p.46). A la cita se puede sumar que los ranchos no son desmantelados una vez que las familias se pasan a vivir a otro lugar. Por ejemplo, las casas de las entrevistadas fueron vendida o heredadas una vez que ellas y sus familias pasaron a residir en el condominio de interés social La Esperanza.

\section{Los Cuadros de Goicochea}

Los Cuadros se sitúa en el distrito de Purral, del cantón de Goicochea. El lugar se encuentra divido en 10 sectores $^{7}$ : La Lupita, Las Amelias, Sector 1, Sector 2, Sector 3, Sector 4, Sector 5, Sector 6, El matadero y Colochos (Munguía Paíz, y otros 2011). Los Cuadros nace en 1983 bajo el gobierno de Luis Alberto Monge Álvarez y con la participación directa del Frente Democrático de la Vivienda (FDV) y el Partido Liberación Nacional. El FDV buscaba crear un proyecto habitacional en el cantón, acción que logra al emplear la modalidad de "un asentamiento informal inducido, con la meta de legalizar su situación a posteriori, mediante la incorporación de vivienda e infraestructura" ( $p$. 26), esto en dos fincas pertenecientes a la Caja Costarricense del Seguro Social que tenían por nombre Cuadros Norte y Cuadros Sur.

Al lugar se trasladan 920 familias (representando aproximadamente 5,060 personas), las cuales, una vez instaladas, debieron auto organizarse para conseguir la conexión de los servicios básicos. Hecho que denota "que esta comunidad históricamente ha adolecido de una falta crónica de equipamiento social y de servicios que permita satisfacer las demandas de su creciente población" (p. 6). Doña Rosa aporta a lo mencionado: "Los Cuadros siempre siempre ha sido poblado por precarios, casi la mayoría, aún más, las casas que están ahora levantadas eran ranchos" (Rosa, comunicación personal, 10 de abril 2018).

Con respecto a las características laborales, en el sitio no abundan los empleos especializados, sino más bien los no calificados o semicalificados (datos de balance de ATAPS para el 2011). Sobre la existencia de asentamiento informales, se conoce

7 "algunos (...) han recibido alguna denominación relacionada con la dinámica social que se desarrolla en los mismos, existen diferencias de nombres de acuerdo a quien suministre la información" (Munguía Paíz, y otros 2011, 28). que existen alrededor de seis: Cervil, Margarita Penón I, Pastos Verdes, Detrás de Las Amelias, Colochos y La Lucha.

Asimismo, existen una serie de problemáticas como "inseguridad, drogadicción, delincuencia, casos de violencia intrafamiliar, desempleo, entre otros" (Hidalgo, 2013, p. 4). Las cuatro jefas de hogar admiten la existencia de dichos problemas, pero consideran que la situación ha mejorado, por ejemplo doña Consuelo indica: "Es más seguro, es como más tranquilo un poquito verdad, un poquito más tranquilo, más más seguro (...) ultimadamente yo he visto que se ha bajado mucho la delincuencia" (Comunicación personal, 12 de abril 2018). Este cambio se puede atribuir a que, "los chiquillos pintillas ya son adultos, ya son papás, ya son hombres, o que han entrado a la cárcel y ya han salido" (Rosa, comunicación personal, 10 de abril 2018). 


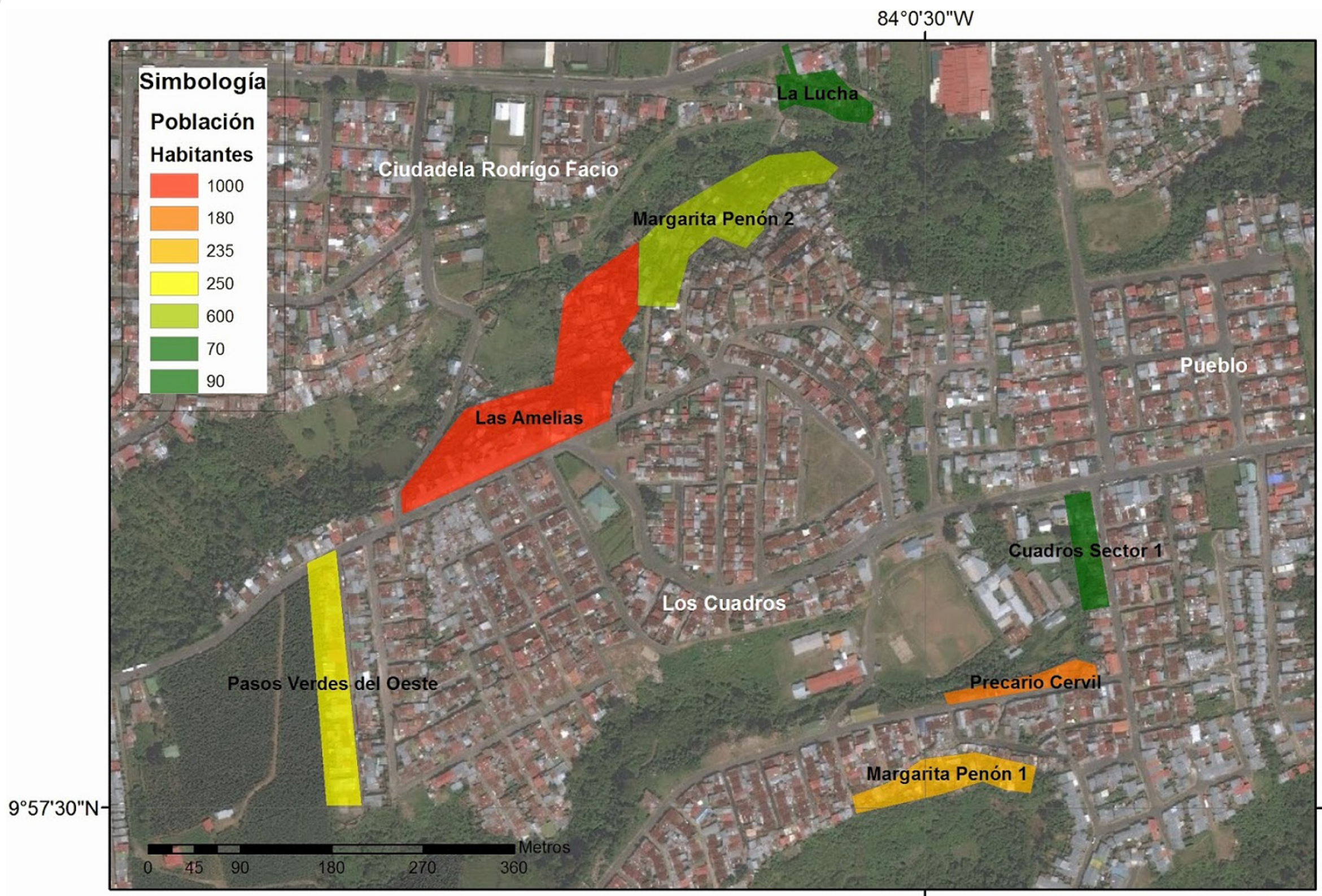

Cartografia Digital: May, Julio. Disponible en linea: http://julsofthepeople.blogspot.com/

$84^{\circ} 0^{\prime} 30 " \mathrm{~W}$

Figura 2. Mapa de Los Cuadros.

Fuente: http://sigmalatam.blogspot.com (2014).

\section{Un hogar entre latas}

Amelias 3 se localiza en el límite este de Los Cuadros. El asentamiento cuenta con una bajada pronunciada (Ver figura 3) que termina en la Quebrada Mozotal. El suelo del lugar es un relleno entre tierra y residuos sólidos (haciéndolo poco estable). Además "Cuenta con una población aproximada de 155 familias, está propiedad perteneciente a una compañía agrícola (...) el primer poblador de la comunidad llegó aproximadamente hace 25 años" (Solera Porras, 2019). Asimismo, sus características físicas no se diferencian de otros precarios del lugar (según indican las entrevistadas).

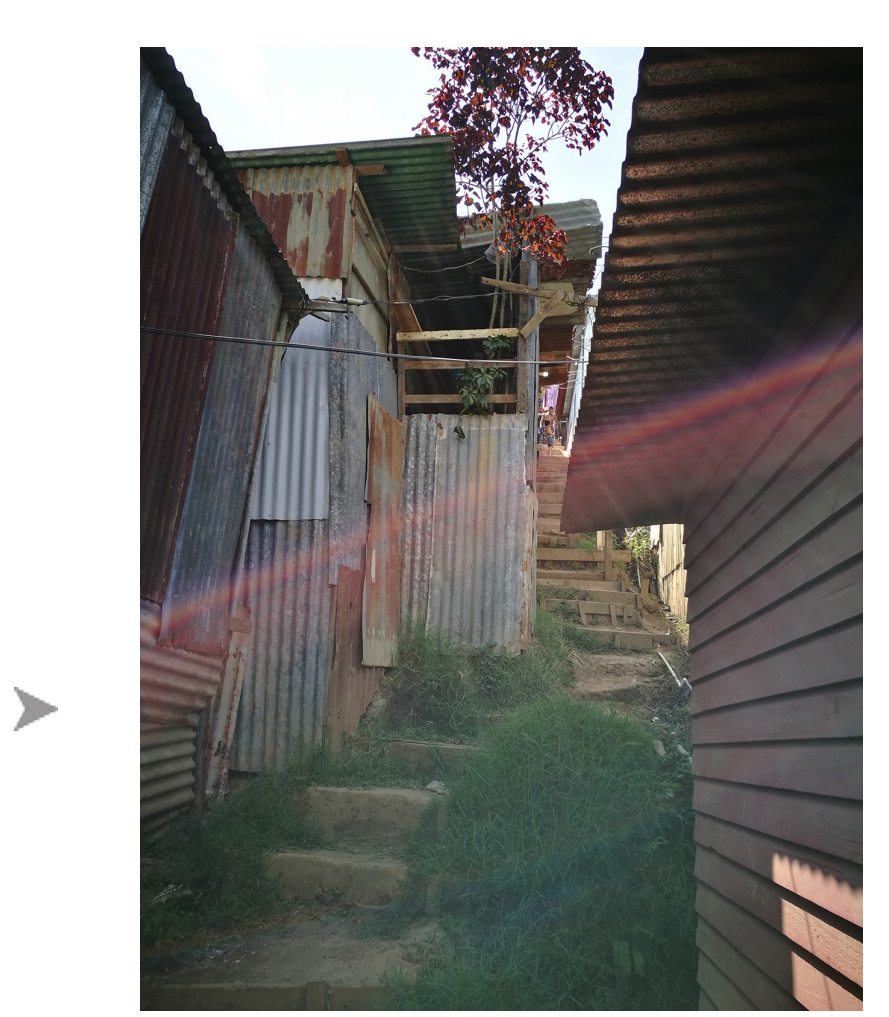

Doña Rosa expone acerca del origen del precario: "De Amelias 1 salió Amelias 2 y Amelias 3 ¿ya? y el precario de nosotros son los hijos que viven en la urbanización que son Amelias 2 (...) entonces eso es una cadena." (Comunicación personal, 10 de abril 2018). En otras palabras, cada nueva generación fue solucionando su problema de vivienda a través de la toma de terrenos, por lo que se muestra como una práctica habitual y normalizada.

Con respecto a la llegada de las jefas de hogar a Amelias 3, encontramos que, la señora Margarita termina ahí debido a la imposibilidad de continuar pagando el alquiler de su anterior apartamento. Historia similar acontece para doña Rosa y doña Luz. Estos hechos muestran cómo el ingreso económico es vital al momento de optar por vivir en un asentamiento informal. Por su parte, la señora Consuelo se traslada al lugar al no poder soportar el ambiente de donde residía (lo consideraba altamente peligroso y de mala influencia 
para sus hijos). De manera que ella y su pareja buscaron un espacio más tranquilo para vivir, el cual terminó siendo el asentamiento.

Dentro del lugar existe un sistema de venta y alquiler de viviendas, esto a pesar de que no existen títulos de propiedad y de que el terreno es propiedad de una compañía agrícola (Solera Porras, 2019). Pero como nos explica doña Consuelo: "el que va a comprar un ranchito no compra la tierra por que no es de nadie eso tiene dueño pero en ese momento ellos te venden en si lo que ellos tienen ahí parado" (Comunicación personal, 24 de marzo 2018), hecho que reafirma doña Rosa: "vea, cuando usted vive en precario usted es dueño de la lata, del terreno no, porque uno invade" (Comunicación personal, 24 de setiembre de 2016).

El sistema de compra se da de dos formas: una es la verbal y la otra a través de un documento escrito (el contenido del documento varia de caso a caso). Con respecto al documento, doña Luz indica, "me dieron una hoja toda rota manchada de café, una firma de la dueña, diciendo que me vendía el rancho a mí, que nadie me podía sacar" (Comunicación personal, 8 de octubre de 2016). A su vez, doña Consuelo menciona: "uno lo que hace es que da su número de cédula, el vendedor da su número de cédula y ambos hacen un papelito cada uno firmado por los dos y ya" (Comunicación personal, 24 de abril de 2018). Con respecto a los costes de venta y alquiler, doña Rosa y doña Margarita señalan que el costo mensual de alquiler puede rondar los 60,000 colones, mientras que el precio de venta va desde un millón y hasta los tres millones de colones.

Se puede indicar que el sistema de venta y alquiler del asentamiento se basa principalmente en honrar los acuerdos suscritos. Ya que, por ejemplo, el documento escrito no tiene ningún sustento legal y su único respaldo es la firma del antiguo dueño de la casa. Así también es posible observar cómo la ausencia de formalidad y regulación, no es impedimento para crear un sistema inmobiliario, el cual cuenta con sus propias formas de trabajo y legitimación.

Una vez indicado cómo es el sistema de venta, se debe pasar a escribir sobre las viviendas (conocidas como ranchos). La señora Luz dice: "cuando yo compré ese ranchito lo que le sostenía al techo de arriba era un poco de bicicletas viejas, es decir no tenía el sustento, es decir no tenía un clavo pegado (...) al principio era tierra no tenía paredes, era como un cajón, es decir tenía paredes pero como las divisiones no (...) el baño a afuera en el patio de hueco" (Comunicación personal, 8 de octubre 2016). Por su parte, doña Margarita dijo que ella vivía rodeada de cuatro latas ${ }^{8}$, en un espacio que podría ser de $40 \mathrm{~m}^{2}$. Para finalizar, la señora Consuelo comenta: "hicimos un cuarto para nosotros y les dejamos los dos cuartos a ellos en la primera parte (...) después quedaba el baño y el excusado, jverdad!, y así habíamos hecho una parte donde podía lavar yo a mano, ¿ve? y en medio quedaba la cocina (...) ya tenía piso aquel, pero solo una partecita a la entrada porque para allá ya era tambo" (Comunicación personal, 24 de abril de 2018).

Con base en lo conversado con las jefas de hogar y lo observado en una visita realizada al asentamiento, es posible indicar que las viviendas se caracterizan por utilizar materiales que estén a la mano, o que sean de un bajo costo (en ciertas ocasiones, esto significa que son de baja calidad). Las materias primas para elaborar las paredes y el techo suelen ser latas de zinc y tablas de madera. El piso se acostumbra a dejarlo en tierra (esto en los primeros momentos de la casa). Por otro lado, a medida que los ingresos económicos lo permitan, se van a ir realizando inversiones en los ranchos. Esto con la intención de mejorar las condiciones físicas del lugar y volverlo un espacio más cómodo.

8 En un comentario fuera de la entrevista, sus hijas indicaron que su mamá siempre procuró tener la casa muy bonita, aseada y con todo lo necesario. Lo que la hacía destacar por sobre la mayoría de los ranchos.
En las siguientes imágenes se puede apreciar parte del asentamiento y algunos de los materiales que forman los ranchos.

La manera bajo la cual los pobladores del asentamiento consiguen los servicios básicos es a través del desvió ilegal de los mismos hacia los ranchos, esto se debe principalmente a su condición de irregularidad y, al hecho de que no son dueños de la tierra. Además, tales factores dificultan la solicitud de ciertos servicios públicos por la vía legal9 "el agua éramos pegados. Así teníamos un tubo, jverdad! (...) a cable, del cable pegábamos (...) ajáa, ajáa, dentro de las casas (...) ya había luz, porque igual la luz eraaa, robábamos luz porque sinceramente robamos luz porque nunca pagamos" (Luz, comunicación personal, 8 de octubre 2016). 
Figura 4. Frente de Amelias 3 Fuente: Elaboración propia.

Figura 5. Costado izquierdo del asentamiento Fuente: Elaboración propia. permisos correspondientes, los interesados se encuentran con el hecho que debido a su condición de informalidad se les suele negar su solicitud.
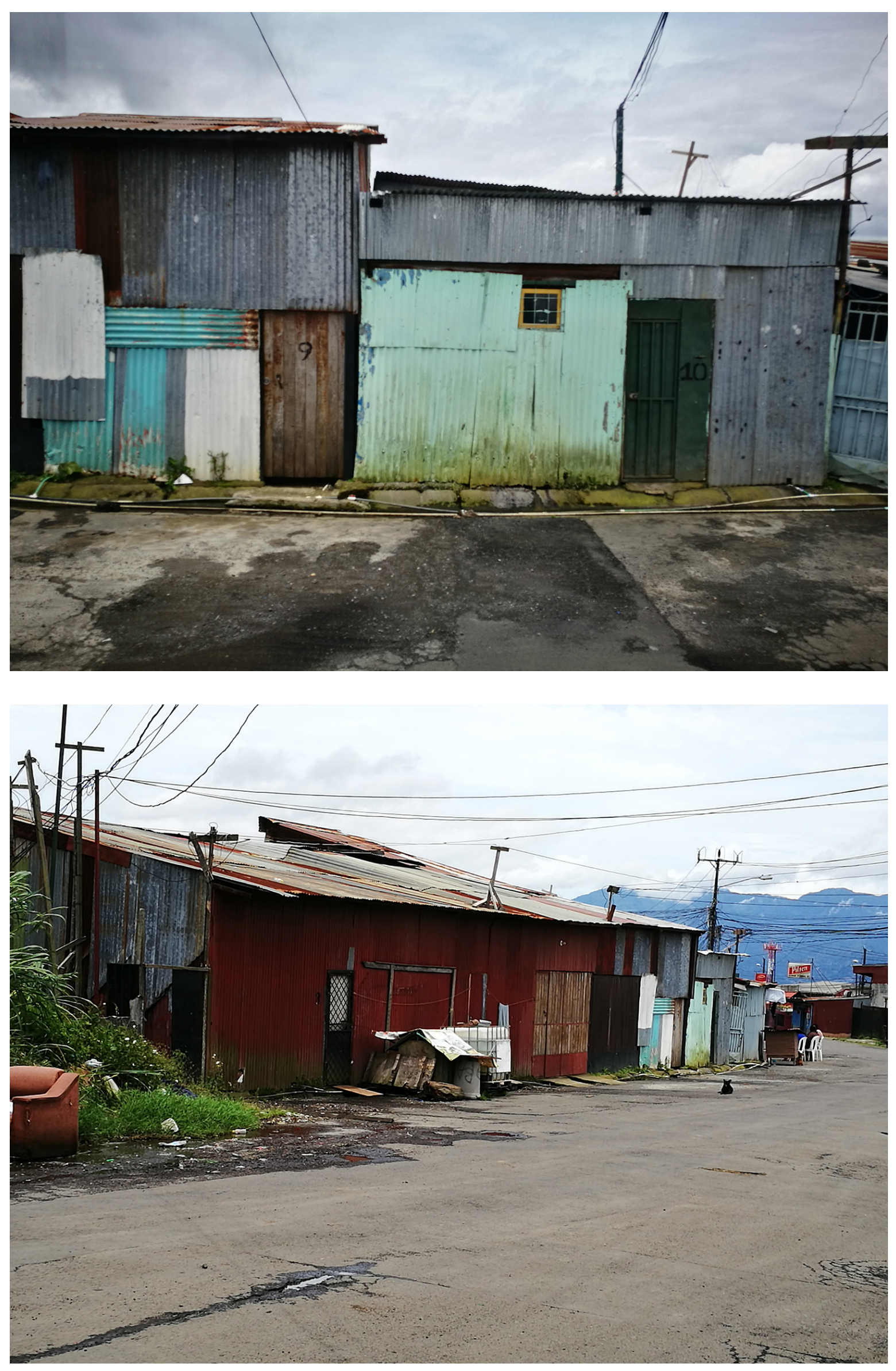

Doña Margarita argumenta que la distribución de agua se realiza a través de un tubo madre que cada familia va desviando hacia su rancho mediante la colocación de una llave de paso. En el caso de la electricidad, "la luz, como la luz no es en sí propia, los cables están desordenados, entonces para llevar la luz a la última casa, entonces tienen que pasar a veces hasta encima de los otros ranchos" (Consuelo, comunicación personal, 24 de marzo de 2018). Se debe tener presente que el riesgo de corte de los servicios puede producirse en cualquier momento y que cada familia es consciente de ello.

A partir de las palabras de doña Luz y doña Margarita, se señalan dos elementos; el primero es el uso de las instalaciones públicas para conseguir los servicios básicos. El segundo elemento es que más allá del gasto económico por el trabajo de desviar los servicios y de arreglar algún problema, no existe una cuota o cobro mensual por el uso de estos.

Por su parte, el clima representa un factor de riesgo en el asentamiento. Por ejemplo, el uso de latas de zinc como material de construcción provoca que la temperatura interna de los ranchos (y la sensación térmica) tengas variaciones ostensibles según las condiciones climatológicas. Por su parte, durante la época lluviosa se pueden generar 
daños hacia los ranchos debido a deslaves del suelo. Asimismo, las colaboradoras señalan que existe la posibilidad de un incendio, ya que las conexiones eléctricas se realizaron de una manera artesanal y además varios de los cables están muy cerca de los techos.

\section{Ser solidario sin dejarse de nadie}

Después de haber escrito sobre el origen de Amelias 3, cómo llegaron las jefas de hogar al lugar y cómo son las viviendas, es necesario exponer la vida en el asentamiento. Lo primero que mencionan las colaboradoras es que consiste en un lugar donde por un lado, no hay que dejarse de nadie, pero que por el otro lado, es posible ver actos de solidaridad.

\section{Con respecto a los conflictos, Doña Rosa comenta:}

"la ley de aquí de esta zona, bueno la zona de abajo, era, aunque usted este como dicen vulgarmente "cagadito" usted tiene que sacar pecho ¿Por qué? porque si no le dan por la jupa, como dicen, esa es la ley aquí, porque si usted se deja de una persona, lo agarran, pero como dicen "de encargo" (...) usted no es de problemas y llega alguien y a usted le dice algo, usted saca pecho, aunque usted nunca se haya agarrado". (Comunicación personal, 10 de abril de 2018)

A lo anterior, se suma que se debe ser "firme, decisivo, que ellos miraban que porque ellos venían de matones ellos, aaay que no, yo también me decía ¡No!" (Consuelo, comunicación personal, 12 de abril de 2018). Por tanto, de las citas se destaca que, ante un conflicto, es importante defender la opinión personal y no ceder ante presiones y matonismos.

Un factor que produce algunos de los enfrentamientos, es el hecho de que el sitio "no es de nadie". Esta condición provoca que algunos individuos traten de sacar beneficio de la situación, "como ahí era tierra de nadie yyy se peleaban por el agua, se peleaban por los cables de luz, se peleaban por todo, querían pasar encima de uno" (Consuelo, $12 \mathrm{de}$ abril de 2018.). Esta situación de dominio sobre el espacio provoca que sus habitantes deban estar en un estado de alerta ante cualquier posible problema. Por ejemplo, doña Margarita cuenta que un día llegó tarde del trabajo y ocupaba dormir, pero unos vecinos tenían "un escándalo", entonces fue a solicitar que bajaran el volumen, a lo cual se negaron, y por tanto tuvo que amenazar con llamar a la policía, acto que provocó que bajaran el volumen por un momento, pero después de unos minutos prosiguieron con el "escándalo".

Los detonantes de los conflictos son muy diversos. Los problemas, se pueden generar a partir de disputas por el agua, el humo de las cocinas y la electricidad. Asimismo, existen enemistades, rencillas y hasta discusiones que han terminado en agresiones físicas. Inclusive, Doña Rosa comenta que las enemistades podían producir actos de vandalismo hacia las viviendas (robos, o daños totales o parciales hacia el inmueble). En una ocasión, personas del asentamiento se metieron a robar al rancho de un vecino como forma de represalia hacia los conflictos que tenían con él. Sumado a ello, los vecinos, a pesar de saber quiénes realizaron el acto, no hicieron ninguna denuncia debido a que luego podían sufrir desagravios.

Acciones como las mencionadas propician que, al momento de efectuar las entrevistas, se indique que vivir en Amelias 3 representa un ambiente pesado, intranquilo y de mala influencia para los menores de edad ${ }^{10}$. Doña Margarita señala que la vida en el

10 Es necesario hacer notar que en términos generales, las personas del asentamiento son descritas como buenas y trabajadoras. A lo que se añade que los conflictos son propiciados por un pequeño grupo de individuos. asentamiento es muy dura, y que para ella es mejor: "quedarse en la casa y compartir lo mínimo". O como nos dice doña Rosa: "siempre ha habido esa regla aquí en esta zona donde uno vive, si usted vive en su casa y no se mete en la otra, usted no tiene problemas con nadie" (Comunicación personal, 10 de abril de 2018).

Pese a la caracterización negativa que se hace del asentamiento, los vecinos y vecinas suelen unirse para hacer frente a problemas comunes o emergencias. Un ejemplo de ello es cuandooo un rancho se veía afectado por las lluvias, "digamos cuando se fue un ranchito, nunca se me olvida, se unían varios, llegaban yy le ayudaban a sacar toda la tierra, el escombro." De estos actos da fe, doña Margarita menciona que, una vez sufrió 
la caída de su rancho (las lluvias generaron un deslave del suelo) y que, al momento de reconstruirlo, contó con el apoyo de sus vecinos.

Una vez a la hija menor de doña Margarita le cayó encima una olla con agua hirviendo y le generó serias quemaduras, por ello, "entre todos los vecinos ayudamos, para ayudarle a ella (Doña Margarita) con los pases, con la comida con el cuido de los chiquitos" (Rosa, comunicación personal, 10 de abril de 2018). Este ejemplo es señalado por doña Consuelo como un momento de humanidad ${ }^{11}$ y que, como tal, propició que se diera la ayuda. Para doña Margarita y varias de las colaboradoras, uno de los puntos altos de vivir en un asentamiento informal es el apoyo que existe en los momentos de emergencia.

En contraste, para doña Consuelo, los actos de solidaridad no son comunes, ya que a ella y a su familia nadie le brindó ayuda cuando sufrió problemas con su rancho. A pesar de ello, decanta otras formas de unión, las cuales se presentan cuando existe un problema que atañe a varios vecinos: "¿Eso sí! Que si a mí me convenía arreglar eso porque diay no hay vuelta de hoja lo hacíamos" (Consuelo, comunicación personal, 10 de abril de 2018). Por ejemplo: "nosotros no tenemos medidor, entonces ¡Pa! Se iba la luz, entonces entre todos se unían, poníamos plata para cambiar el cableado yyy fulanito y menganito ponían la luz" (Rosa, comunicación personal, 10 de abril de 2018).

Otro caso, además del anterior, se daba cuando "la pasada" (gradas comunales que dan acceso a las entradas de los ranchos) necesitaba arreglo, motivo por el cual cada quien reparaba o fortalecía su parte, de manera que no existiera peligro al caminar por esta. Finalmente, el último ejemplo a nombrar es cuando se impidió la venta de un rancho porque se tenía conocimiento de que lo iban a convertir en un bunker para consumo de drogas.

La unión y solidaridad demuestran la existencia de una red de apoyo y ayuda dentro del asentamiento. Esta se activa en aquellos momentos que algún vecino o vecina ocupe del apoyo de las personas del lugar o cuando se presentan una situación que afecta el diario vivir de todos los residentes. La existencia de la red permite a sus habitantes llevar la vida en Amelias de una manera más grupal y menos individual, además, les posibilita paliar algunas de las dificultades que conlleva el vivir de manera irregular y en condiciones de pobreza.

Ante las situaciones de conflicto y solidaridad expuestas, se marca que la cotidianidad de los pobladores del precario discurre entre estos dos extremos, en donde, por un lado, se está en un estado alerta ante cualquier problemática, pero por el otro, se cuenta con la tranquilidad de saber que ante alguna emergencia o necesidad los vecinos van a estar ahí para brindar su apoyo.

\section{Conclusiones}

Primeramente, Amelias 3 nace a partir de la necesidad de vivienda de un grupo de personas, las cuales emplearon el mismo método que sus padres y abuelos, es decir la invasión y toma de un terreno. Esta acción a su vez se encuentra íntimamente relacionada con la manera en que nació Los Cuadros. Por lo que es posible establecer que la creación de asentamientos irregulares para dar solución a necesidades de vivienda es y ha sido una práctica regular en Los Cuadros. Asimismo, existe un mercado inmobiliario informal en Amelias 3, este se caracteriza por estar consolidado y por tener normativas y reglas propias.

Por otro lado, el asentamiento cuenta con una serie de condiciones físicas de riesgo (por ejemplo, la base del suelo y el estar construido sobre una pendiente pronunciada). A esto se le suma que el estado de las viviendas no es el más adecuado, pues los materiales de construcción no son los mejores y, además, presentan ciertas complicaciones (por ejemplo, la existencia de goteras). En tanto, las conexiones de los servicios son deficientes y en algunos casos precarios, por lo que las posibilidades de incendio son altas (esto basado en las conversaciones llevadas a cabo con las colaboradoras).

A nivel social, se destaca el hecho de que la tierra "no es de nadie", condición que posibilita que las reglas y dinámicas sociales sean un producto exclusivo de sus 
habitantes. Ello provoca que en ciertas ocasiones se dé una lucha por el poder y control del lugar, tal y como señalan las jefas de hogar en las citas. Ante esta situación, algunos residentes desarrollaron una actitud de defensa y resistencia, caracterizada por "no dejarse amedrentar".

Para finalizar, se tiene que, si bien es cierto, Amelias 3 es descrito como un lugar tenso para vivir, existe una relación de apoyo y soporte entre los vecinos, los cuales se unen en aquellos momentos en que se dan afectaciones a todo el grupo (desconexión de los cables de luz o daños en las estructuras comunales), o en casos individuales con carácter de urgencia (derrumbes parciales o totales de los ranchos 0 emergencias humanitarias). Ello muestra la existencia de una red de colaboración, la cual se activa cuando las condiciones así lo ameriten. Esto posibilita que los pobladores no estén completamente solos ante los apremios de vivir en un asentamiento informal y en condición de pobreza.

\section{Referencias Bibliográfícas}

Abramo, P. Mercado informal y producción del hábitat: la nueva puerta de acceso a los asentamientos populares en América Latina. En Los lugares del hábitat y la exclusión, de Teolinda Bolivar y Jaime Erazo Espinoza, 29-58. Quito: FLACSO, 2011.

Bäbr, Jürgen, y Borsdorf, A. La ciudad Latinoamericana. La construcción de un modelo. Vigencia y perspectivas. Urbes II, $n^{0} 2$ (2005): 207-221.

Centro Cooperativo Sueco. Suelo urbano y vivienda popular en América Latina. 2003.

Chacón, E. (2016) Causas y consecuencias de las nuevas políticas de vivienda de interés social costarricense. [Tesis de licenciatura en Trabajo Social, Universidad de Costa Rica]

Cruz, D. (2017). ¿Hacia la verticalización de la política de vivienda? Los casos de los Condominios Horizontal-Vertical Las Mandarinas y Los Olivos ubicados en el Gran Área Metropolitana como respuesta a la demanda de vivienda proveniente de asentamientos en condición d. [Tesis de licenciatura, Universidad de Costa Rica].

De Sárraga, A. (2020). Cambio en las relaciones vecinales al efectuarse un traslado de un asentamiento informal a un condominio de interés social, a través de la mirada de tres familias, en Los Cuadros de Purral, Goicochea, San José. [Tesis de Licenciatura indicar grado Universidad de Costa Rica] [Sin publicar]

Fundación Promotora de la vivienda. Informe Nacional: Situación de vivienda y desarrollo urbano en Costa Rica. San José, 2018.

Harvey, D. Urbanismo y desigualdad social. Traducido por Marina González Arenas. Siglo XXI, 1977.

Hidalgo, P. (2013). Criterios técnicos sociales. Proyecto "La Esperanza”. Fundación Promotora de Vivienda. Moravia.

Instituto Nacional de Estadística y Censo. (2013). X Censo Nacional de Poblacion y VI de Vivienda: Principales indicadores sobre asentamientos informales. San José.

Méndez, J. A. (2011). Las representaciones sociales de los habitantes de San Rafael de Escazú: su importancia en la determinación de los elementos constitutivos de la identidad de los grupos de altos ingresos económicos. [Tesis de licenciatura Universidad de Costa Rica]

Morales, M. Pobreza, participación y costos sociales del crecimiento urbano en ciudades intermedias. Algunas reflexiones teóricas. Geográfica de America Central, $n^{0} 19-$ 20 (1984): 11-29.

Morgan, D. (sin fecha). La evolución política de vivienda en Costa Rica a partir de 1986.

Munguía, Y., Lorz, R., Granados, R. y Jiménez, R. (2011). Los Cuadros Purral, Goicoechea. Diagnóstico comunitario enero-junio 2011. Ministerio de Vivienda y Asentamientos Humanos. San José. 
ONU Hábitat. (2015). Temas Habitat III: 22- Asentamientos Informales. Nueva York.

Vargas, P. (2009). Representaciones sociales de la pobreza y de las políticas públicas orientadas a tratarla en el asentamiento precario de Las Palmas, Los Guido, Desamparados, San José, Costa Rica [tesis de licenciatura). Universidad de Costa Rica]

Rapaport,A. (1988). Asentamientos espontáneos como Diseño Vernáculo. Spontaneous Shelter, International perspective and propects, Universidad de Temple. Philadelphia: Temple University Press,

Restrepo, E. Etnografía. Alcances, técnicas y éticas. Segunda. Lima: Fondo editorial de la Universidad Nacional Mayor de San Marcos, 2018.

Solera, S. (2019) Implementación de la vivienda vertical para el enriquecimiento de los espacios públicos, estrategia participativa en zonas de riesgo social, comunidad, Amelias 3 Goicoechea. "Manuscrito en preparación". [Tesis, grado, Universidad de Costa Rica] [Sin publicar]

Vasilachis de Gialdino. (2013). Pobres, pobreza, identidad y representaciones sociales. Barcelona, Editorial Gedisa. 